\title{
Research on Influencing Factors of Purchase Promotion Intention Based on Skincare Industry
}

\author{
Zhichao Liu, Jiahui Ling \\ School of Business Administration, South China University of Technology, Guangzhou, China \\ Email: bmzhcliu@scut.edu.cn, chrisling0516@163.com
}

How to cite this paper: Liu, Z.C. and Ling, J.H. (2019) Research on Influencing Factors of Purchase Promotion Intention Based on Skincare Industry. Modern Economy, 10, 1033-1047.

https://doi.org/10.4236/me.2019.103069

Received: February 21, 2019

Accepted: March 25, 2019

Published: March 28, 2019

Copyright $\odot 2019$ by author(s) and Scientific Research Publishing Inc. This work is licensed under the Creative Commons Attribution International License (CC BY 4.0).

http://creativecommons.org/licenses/by/4.0/

\section{(c) (7) Open Access}

\begin{abstract}
The experience economy is known as the latest economic development model in the 21 st century, accompanied by a high degree of attention and research on experiential marketing. This paper aims to study the influencing factors of consumers' purchase intention in experiential promotion by taking the offline promotion as the foothold and taking the skin care market as the starting point. This study refers to the previous research on the scale of experience and the intention of purchasing, to design questionnaires and conduct targeted consumer research. Factor analysis is used to extract the factors with high correlation of each dimension. At the same time, regression analysis is used to test whether the four dimensions of experiential promotion have an impact on customer purchase intention. This concludes the main factors affecting consumers' purchase intentions in experiential promotion activities, and provides reference for the long-term development of experiential promotion activities and skin care products industry.
\end{abstract}

\section{Keywords}

Experience Marketing, Experiential Promotion, Purchase Intention, Skin Care Industry

\section{Introduction}

According to the definition of the American Marketing Association, promotions are a variety of corporate marketing campaigns that stimulate consumer purchases and dealerships in addition to personal promotions, advertising, and promotional reports. Well-known marketing scholar Philip Kotler (1988) believes that promotion can stimulate consumers' purchases and provide additional motives for purchases; promotions can increase the added value of goods 
and change consumers' psychological price or value perception of branded goods, thus achieve fast purchase or bulk purchase [1]. Koppalle (1996) believes that consumers' purchase decisions are influenced by promotion decisions, mainly in two aspects: first, promotions reduce the cost of money paid by consumers; second, consumers get more value than the goods themselves through promotions [2]. In order to promote their purchasing decisions, Raghubir (2004) believe that the impact of promotion on consumers includes not only economic money or non-money benefits, but also the promotion reduces the trading time of consumers and simplify the purchase process [3].

Based on the local, Chinese scholar Li Xianguo (1998) mentioned in earlier academic research that promotion is a means and method for enterprises to promote consumers to buy goods or services through various short-term incentives [4]. The biggest feature of the promotion is the rapid growth of sales in a short period of time. In the recent related research, Jinyun (2013) believes that there are many ways to promote activities. Different promotions can bring different perceptions to consumers, causing different reactions of consumers, thus achieving different promotional purposes [5]. Therefore, the effect of the promotion depends not only on the promotion of the company, but also on the promotion method adopted by the company.

China's cosmetics market has become the world's largest emerging market, with hundreds of thousands of products, and new products are dazzling. Among them, skin care products are the fastest growing segment of the entire cosmetics industry. In recent years, the average annual growth rate has reached $15 \%$ and above. But we also want to see that the brand concentration of the skin care industry is relatively low. The top ten brands in the industry account for less than $50 \%$ of the market [6]. Compared with other industries, the purchase of skin care products is more susceptible to consumption.

This article takes the skin care industry as the research object, explores the incentives that the promotion activities impress consumers, refers to the previous research on the experience dimension and the purchase intention, and designs the questionnaire and conducts targeted consumer research. Factor analysis is used to extract the factors with high correlation of each dimension. At the same time, regression analysis is used to test whether the four dimensions of experiential promotion have an impact on customer purchase intention. This concludes the main factors affecting consumers' purchase intentions in experiential promotion activities, and provides reference for the long-term development and trial of experiential promotion and skin care products industry.

\section{Literature Reviews}

\subsection{Experience Marketing}

The concept of experiential marketing was first proposed by Schmitt (1999) in 1999 [7]. In its discourse, experiential marketing is "a marketing and management model driven by experience", and he also predicts that experience market- 
ing will gradually replace traditional marketing, which is based on functional appeal and interest appeal. The importance of emotional appeal and atmosphere will gradually be recognized [8].

In China, research on experiential marketing focuses more on specific marketing strategies and implementation practices. Fan Xiucheng et al. (2002), the scholar of Nankai University, pointed out that the core value of experiential marketing is to provide customers with a satisfying and valuable experience, not just to provide products and services [9]. Xie Yuxin (2002) of Zhejiang University proposed eight specific implementation modes of experience marketing [10]. Zhong Caibang (2002), a scholar at Sichuan University, established an experiential marketing research model of "customer satisfaction-customer experience value-customer expectation value" [11].

Combining the research and understanding of experience marketing by predecessors, we can see that experience marketing is actually the same as the concept of commodity marketing and service marketing that we mentioned earlier [12]. Commodity marketing focuses on the selling point of the enterprise itself. Service marketing is the selling point of the detached goods itself to provide high-quality additional services. The so-called experience marketing is inseparable from providing consumers with a high-quality experience. Through experience, the company will gradually focus on the value of the product itself and gradually add value to the experience link, and consumers will be able to transfer their monetary value for this experience because they have gained a unique and profound experience in the atmosphere created by the company [13].

At the same time, because experience marketing is a marketing method that emphasizes psychological satisfaction beyond material satisfaction, enterprises often should work hard for this, and have higher requirements in the aspects of atmosphere creation, environment creation, scene design, and process control [14]. Therefore, in the process of creating a good experience marketing, the company should pay attention to the details, improve the quality, pay attention to the brand concept and strategy formulation conveyed in the experience marketing and maintain the unity and coordination with the overall marketing plan of the enterprise [15].

\subsection{Terminal Promotion}

At present, the research on the behavior of consumer promotion in academic circles mainly includes three aspects: 1) Empirical research on the quantitative measurement of actual output such as sales volume, market share and brand conversion (promotional effect research) [16];2) Promotion of consumers Research on statistical characteristics, psychological characteristics, and purchasing behavior characteristics (promotional consumer research) (Jha-Dang, 2006) [17]; 3) Based on consumer psychology, explain the reasons consumers respond to promotions. (Research on the mechanism of action of consumer promotion reaction behavior) [18]. 


\subsubsection{Research on Consumer Promotion Tendency}

Consumer promotion propensity research involves two dimensions: the relationship between promotion propensity and individual characteristics, and the relationship between promotion propensity and purchase characteristics. Promotional propensity is the key link. Some scholars believe that the promotion tendency is universal, that is, if a consumer changes his behavior because of a promotion method, he will also respond to other promotion methods (Shimp et al., 1984) [19]. Other scholars believe that consumers only have a tendency toward certain promotion methods (Lichtenstein et al., 1995) [20]. As the research progresses further, the academic community generally recognizes the second concept, so different academic studies begin to focus on different propensity to explore the relationship between individual characteristics of consumers or consumers' purchasing behavior (Lichtenstein et al., 1997) [21].

Factors that affect consumer promotion use include: availability of promotional methods, price levels, product characteristics, shopping environment, and so on. Individual characteristics of consumers are an important aspect of this (Bawa et al., 1987) [22]. Individual characteristics that influence consumer propaganda tendencies fall into three broad categories: statistical characteristics, psychological characteristics, and cost/reward perception (Mittal, 1994; Martinez et al., 2006) [23].

\subsubsection{Consumer Response Mechanism for Promotional Behavior}

1) Conditional reflection theory

Classical conditioning theory provides a scientific systematic explanation and inference of consumer behavioral responses to promotional incentives given prior to purchase. For example, in the face of "price discounts", consumers' behavioral responses; while operational conditioning provides a systematic explanation and prediction of consumer behavioral responses to promotions that are rewarded after purchase, such as "sweepstakes", etc. [24].

2) Consumer perception theory

Consumer perception theory's interpretation of consumer promotion response focuses on the consumer's internal cognitive process, especially how consumers perceive the environment [25]. Consumer perception theories related to consumer promotion responses include attribution theory, assimilation-contrast theory, outlook theory, and psychological account theory. These theories reveal how consumers perceive various promotions and the impact of these consumer perceptions on their behavioral responses.

Festinger (1957) proposed Cognitive Dissonance Theory: People often seek consistency in their understanding for their inner peace and harmony. In a promotion, if a consumer is dissatisfied with the product or service that he or she purchased in the promotion, there is a high probability that the cognitive disorder will occur [26]. They may change their attitudes (inferring that the promotional items are not good or the quality of the promotional brand itself is 
not good), changing the behavior (not buying promotional items in the future or not buying the branded products in the future), collecting more information (From other aspects to comfort your promotional items is also good) and other ways to eliminate cognitive disorders.

Attribution theory (Attribution Theory) mainly describes how consumers explain the causes of some events. According to the attribution theory, the consumer's self-perceived attribution is to pay attention to itself and find the reason for the purchase from the self [27]. Foreign object perception attribution focuses on the purchase of products, as well as the perceived attribution of others that focus on the ideas of other stakeholders (such as promoters) in the purchase process.

Assimilation-contrast theory believes that the degree to which some marketing information changes the consumer's initial belief in a product depends on the difference between the consumer's initial belief in the product and the location of the product in the consumer's newly accepted marketing message [28]. New information that differs little from the initial beliefs is easily assimilated by the original beliefs, and new information that differs greatly from the original beliefs is in sharp contrast to the original beliefs.

Kahneman and Tversky (1979) proposed Prospect Theory, which argues that consumer decision-making depends on consumers' measurement and judgment of possible benefits or possible losses in the purchase decision process [29]. According to the outlook theory, people have two stages in the decision-making process: depicting the decision-making stage and the evaluation stage. In the stage of depicting the decision-making, people use various methods to simplify the decision-making problem and compare the various outcomes of the decision-making with the same reference point. In the evaluation stage, Kahneman and Tversky (1979) proposed the value function of the S-type. The value function is defined according to the gain or loss relative to a reference point, the concave gain and the convex loss [30].

The Mental Account Theory (Mental Accounting Theory) has further developed the outlook theory. Psychological account theory believes that consumers' evaluation of purchase transactions is the sum of their transaction value and other acquired value. Therefore, frequent promotions may change the original reference price of the product in the consumer's mind, thereby reducing the transaction value of the product and affecting the perceived value of the product.

3) Attitude behavior relationship theory

The study of attitude and behavior relationship theory focuses on how to make consumers' feelings and attitudes towards promotion activities into actual purchase behaviors [31]. Consumers will really generate purchase intentions and ultimately make purchase decisions because of the promotion activities. The willingness of consumers to purchase behaviors due to promotional activities depends on two aspects. On the one hand, it depends on consumers' judgment on the results of shopping using the promotion, and on the other hand, on the sub- 
jective behavioral norms of consumers. That is, the consumer's evaluation of the promotion of society and others and the confidence and motivation of consumers to follow these evaluation concepts.

\section{Theoretical Basis and Research Hypothesis}

\subsection{Experience Dimension}

For the dimension and division of experience, Lofman divides the experience into six aspects: scene, emotion, thinking, action, feeling and evaluation [32]. The famous scholars Pine and Gilmore divide the experience into the ordinate and the recognition as the ordinate, escape, entertainment, and aesthetics; Schmit also proposes a five-dimensional experiential strategy module for senses, emotions, thoughts, behaviors, and connections; Brakus divides experience into five dimensions: sensory, emotional, intellectual, physical, and social based on cognitive theory [33].

Reviewing relevant domestic research, Zhou Zhaoqing combines Schmitt and Maslow's research theories to divide the experience into three dimensions: emotion, entertainment and culture [34]; Chen Jianxun divides the experience into negative experience, no experience, low experience, moderate experience and height. Experience 5 levels [35].

Integrate the above research viewpoints, consider the uniqueness of the skin care industry and experience promotion activities, and combine the actual situation of brand experience promotion to divide the measurement into four major experience dimensions. Each experience dimension roughly contains two related factors. Including: experience mode (thinking, behavior), experience environment (sensory, scene), experience personnel (social, association), experience promotion (emotion, culture).

Based on the above theory and research basis, we make the following assumptions:

H1a: In the skincare industry experience terminal promotion, the experience mode is related to the customer's brand experience.

H1b: In the skincare industry experience terminal promotion, the experience environment is related to the customer's brand experience.

H1c: In the experience-based terminal promotion of the skin care industry, the experience personnel have a correlation with the customer's brand experience.

H1d: In the skincare industry experience terminal promotion, experience promotion has a correlation with the customer's brand experience.

\subsection{Purchase Intention}

Based on the research of well-known scholars by Beerli et al. (1999), we will evaluate the individual's response to advertising/promotion in the three stages of Cognitive-Emotional Conation [36]. The purchase intention is the most common measurement dimension applied to the Conation phase. Existing research shows that promotions can stimulate behavioral responses such as consumer 
brand switching, hoarding, accelerated purchases, product trials, more purchases, or more spending (Shi et al., 2005) [37].

Therefore, with reference to the academic research and scales of Shi et al. (2005), we measure the following behavioral responses of consumers to experiential promotions in the questionnaire: brand goodwill, measurement items are "experiential promotions let me A brand produces more good feelings; brand loyalty, the measurement item is "I usually buy the same brand, even when I buy other brands to get a promotional experience"; the purchase acceleration, the measurement item is "experiential promotion" Let me buy a product earlier than planned. Hoarding, the measurement item is "experiential promotion allows me to buy more products", product trial, measurement item is "experiential promotion let me buy me before Products that have never been tried" [38]. In response to these questions, respondents need to choose their own answer from the 5-point Likert Scale. 1 means very disagree, 2 means disagree, 3 means general, 4 means agree, 5 means Very much agree. The choice of the 5-point Likert scale instead of the 7-point Likert scale is mainly because the quality and perceived ability of the respondents are quite different. The 5-point Likert scale makes it easier for respondents to make choices, and the results are more obvious. The final part of the questionnaire asked the respondents to leave information on demographic variables such as gender, age, and income level.

Based on the above theoretical basis and related research, we make the following assumptions:

$\mathrm{H} 2$ : In the skincare industry experience terminal promotion, the brand experience is related to the customer's purchase intention.

\section{Hypothesis Testing}

This questionnaire uses a simple random sampling method that focuses on people who have purchased or used skin care products. The specific survey results are analyzed as follows

\subsection{Descriptive Statistics}

Sample feature analysis, that is, the basic situation of the sample, describes the basic characteristics of the sample, mainly through frequency (frequency) statistical analysis. Because the conclusions of the empirical research are based on the corresponding specific data, the conclusion of leaving the data is empty and lacks scientific basis. It is also possible to lay the groundwork for subsequent research improvements or limitations in the research conclusions by understanding the sample characteristics.

\subsubsection{Analysis of sample characteristics}

Through simple sample characterization, from Table 1 \& Table 2, we can see that among the 151 valid questionnaires collected, 30 males were interviewed by the brand, 121 were female consumers, and the number of females was 4 times that of males. It basically meets the proportion of the gender structure of con- 
sumers in China's current skin care market. Form Table 3, we could tell that among the respondents, the age group is the 36 - 45 age group, followed by the 26 - 35 age group and the 46 - 55 age group. It can be seen that the audience is mainly mature women. This is also basically in line with the positioning and pricing strategy of the skin care industry.

\subsubsection{Importance Sorting}

In the survey questionnaire, except for the v22-v26 five questions for the purchase intention survey, v1-v21 are measurement factors that we think may affect the consumer brand experience. In order to understand the influence of different factors in the minds of consumers, we have obtained the following Table 4 by sorting the initial importance of the survey results.

By ranking the importance, we can know that the top 10 factors, including free product selection, environmental layout, event gift, product composition experiment, etc., are largely related to the product itself or the experience environment. The factors ranked lower, mainly including performing arts performances, star scene promotion and brand endorsement star advertisements, etc., most of which are external factors that have little to do with the product itself. In the promotion activities, consumers are more inclined to pay attention to the environment of the product itself or the experience, and the sensitivity to the celebrity endorsement, performing arts and other driving factors is relatively low. This may be related to the target consumers who are mainly concentrated in older women aged 26 - 45 years and older. They have more mature minds and realistic consumption concepts, and have more stable spending power, and the

Table 1. Sample statistics.

\begin{tabular}{lccc}
\hline Number of samples & Valid sample & 151 & 151 \\
& Missing sample & 0 & 0 \\
\hline
\end{tabular}

Table 2. Gender statistics.

\begin{tabular}{cccc}
\hline & & $\mathrm{N}$ & Percentage \\
\hline & Male & 30 & 19.9 \\
Valid sample & Female & 121 & 79.5 \\
& Total & 151 & 100.0 \\
\hline
\end{tabular}

Table 3. Age statistics.

\begin{tabular}{cccc}
\hline & & N & Percentage \\
\hline & $18-25$ & 25 & 16.6 \\
& $26-35$ & 39 & 25.8 \\
Valid sample & $36-45$ & 54 & 35.8 \\
& $46-55$ & 33 & 21.9 \\
& Total & 151 & 100.0 \\
\hline
\end{tabular}


Table 4. Descriptive statistics.

\begin{tabular}{|c|c|c|c|c|c|}
\hline & $\mathrm{N}$ & Minimum & Maximum & Mean & Std. Deviation \\
\hline free product selection & 151 & 1 & 5 & 4.21 & 0.906 \\
\hline Beautiful environmental layout & 151 & 1 & 5 & 4.19 & 0.862 \\
\hline event gift & 151 & 1 & 5 & 4.10 & 0.964 \\
\hline Promotional staff's skin care knowledge & 151 & 1 & 5 & 4.07 & 0.978 \\
\hline Proper promotion frequency & 151 & 1 & 5 & 4.06 & 0.896 \\
\hline In-person product component experiment & 151 & 1 & 5 & 4.03 & 1.003 \\
\hline Upscale promotion location & 151 & 1 & 5 & 3.95 & 0.948 \\
\hline Soothing ambient music & 151 & 1 & 5 & 3.91 & 1.000 \\
\hline Enthusiastic promoters & 151 & 1 & 5 & 3.91 & 1.029 \\
\hline Distinctive brand concept & 151 & 1 & 5 & 3.91 & 0.897 \\
\hline Long-standing brand story & 151 & 1 & 5 & 3.89 & 0.956 \\
\hline Unique brand image & 151 & 1 & 5 & 3.87 & 0.874 \\
\hline Brand cultivate class & 151 & 1 & 5 & 3.83 & 0.992 \\
\hline Professional skin care class & 151 & 1 & 5 & 3.76 & 1.112 \\
\hline Promotional staff's sales pitch & 151 & 1 & 5 & 3.75 & 1.045 \\
\hline Delicious tea break & 151 & 1 & 5 & 3.66 & 1.101 \\
\hline Close customer relationship & 151 & 1 & 5 & 3.64 & 1.163 \\
\hline Brand endorsement star & 151 & 1 & 5 & 3.63 & 1.135 \\
\hline star scene promotion & 151 & 1 & 5 & 3.48 & 0.999 \\
\hline Free skin care services & 151 & 1 & 5 & 3.46 & 1.136 \\
\hline performing arts performances & 151 & 1 & 5 & 3.41 & 1.121 \\
\hline Valid N (listwise) & 151 & - - & -- & -- & -- \\
\hline
\end{tabular}

chances of impulse purchase are lower.

\subsection{Project Analysis}

\subsubsection{Independent Sample T-Test}

The purpose of the independent sample t-test on the project is to conduct a preliminary test on the data, and delete the item that has not reached the level of significance. The retained item has the degree of discrimination. That is to confirm the identifiable line of each item (with significant difference), otherwise the item is considered to lack credibility and is not suitable for further factor and reliability analysis.

By performing an independent sample t-test on all items and reading the Sig. ( 2 tailed) value, the values of all items are significant, i.e. less than $0.05\left(^{*}\right)$, no need to eliminate the factor.

\subsubsection{Factor Analysis}

In this survey questionnaire, we divided the experience into the following four 
dimensions through relevant literature research and real-life experience activities, including experience mode, experience environment, experience personnel and experience promotion. Relevant factors are provided for testing in each dimension. Through factor analysis, the factors with low correlation in each dimension are eliminated, and several major dimensions and specific factors affecting the effect of brand experience promotion are summarized.

Dimension 1: Experience mode

Dimension 2: Experience environment

Dimension 3: Experiencers staff

Dimension 4: Experience Promotion

From Tables 5-8, we could see that through the factor analysis of the four

Table 5. Common factor variance (Experience mode).

\begin{tabular}{|c|c|c|}
\hline & Initial & Extract \\
\hline In-person product component experiment & 1.000 & 0.629 \\
\hline free product selection & 1.000 & 0.709 \\
\hline Brand cultivate class & 1.000 & 0.666 \\
\hline \multicolumn{3}{|c|}{ Extraction method: principal component analysis } \\
\hline
\end{tabular}

Table 6. Common factor variance (Experience environment).

\begin{tabular}{ccc}
\hline & Initial & Extract \\
\hline Upscale promotion location & 1.000 & 0.671 \\
Proper promotion frequency & 1.000 & 0.730 \\
Beautiful environment layout & 1.000 & 0.740 \\
Soothing ambient music & 1.000 & 0.718 \\
performing arts performances & 1.000 & 0.692 \\
Delicious tea break & 1.000 & 0.693 \\
Extraction method: principal component analysis &
\end{tabular}

Table 7. Common factor variance (Experiencers staff).

\begin{tabular}{lcc}
\hline & Initial & Extract \\
Enthusiastic promoters & 1.000 & 0.673 \\
Free skin care services & 1.000 & 0.736 \\
Close customer relationship & 1.000 & 0.691 \\
Extraction method: principal component analysis & \\
\hline
\end{tabular}

Table 8. Common factor variance (Experience Promotion).

\begin{tabular}{ccc}
\hline & Initial & Extract \\
\hline Distinctive brand concept & 1.000 & 0.655 \\
Endorsement star & 1.000 & 0.688 \\
Unique brand image & 1.000 & 0.782 \\
Extraction method: principal component analysis & \\
\hline
\end{tabular}


dimensions of appeal, we can conclude that in the reference samples of the 151 valid questionnaires, the factors retained in each dimension include the experience mode (in-person product component experiment, free product use choice, brand cultivation class), experience environment (high-end promotional venues, appropriate promotion frequency, exquisite environment layout, soothing environmental music, wonderful performing arts performances and delicious tea breaks), experience staff (enthusiasm promotion attitude, free care service, close customer relationship) and experience promotion (clear brand concept, endorsement star, unique brand image). There is a total of 15 factors in 4 dimensions.

By analyzing and understanding each dimension on a factor-by-factor basis, it is surprising that the experience environment is so important to consumers, and these factors are highly related and integrated. In the dimension of experience and experience, we can see that the traditional and pragmatic promotion methods, including the network economy, are still very important today. This result may also be moderately larger than the brand target consumer group. In terms of life experience and life wisdom, they have their own unique insights. They may value the product itself and the salesperson's service attitude.

\subsubsection{Reliability Analysis}

By analyzing the reliability of the four dimensions after factor analysis, we can see that the Alpha values of the four dimensions are greater than 0.6 in Table 9, so it has good reliability, that is, the result of factor analysis has higher credibility.

\subsubsection{Regression Analysis}

From Table 10 and Table 11, we could see that by regression analysis of the questionnaire v1-v21 (four experience dimensions) and the questionnaire v22-v26 (purchase intention survey), in the model summary, $\mathrm{R}^{2}$ is 0.735 , that is, the model explains $73.5 \%$ of the dependent variables. The model has a good fit. And the consumer's brand experience is basically positively correlated with the purchase

Table 9. Reliability statistics.

\begin{tabular}{ccc}
\hline Dimension & Number of items & Clone Bach Alpha \\
\hline Experience mode & 3 & 0.749 \\
Experience environment & 6 & 0.808 \\
Experiencers staff & 3 & 0.785 \\
Experience Promotion & 3 & 0.783 \\
\hline
\end{tabular}

Table 10. Model summary.

\begin{tabular}{|c|c|c|c|c|c|c|c|c|c|}
\hline \multirow{2}{*}{ model } & \multirow{2}{*}{$\mathrm{R}$} & \multirow{2}{*}{$\mathrm{R}^{2}$} & \multirow{2}{*}{ adjusted $\mathrm{R}^{2}$} & \multirow{2}{*}{$\begin{array}{c}\text { Standard } \\
\text { estimated error }\end{array}$} & \multicolumn{5}{|c|}{ Change statistics } \\
\hline & & & & & $\mathrm{R}^{2}$ variation & F variation & Degree of freedom 1 & Degree of freedom 2 & Significant $\mathrm{F}$ variation \\
\hline 1 & $0.857 \mathrm{a}$ & 0.735 & 0.728 & 0.39487 & 0.735 & 101.349 & 4 & 146 & 0.000 \\
\hline
\end{tabular}

a. Predicted variables: (constant), experience environment, experience mode, experience staff, experience promotion. 
Table 11. Coefficient a.

\begin{tabular}{|c|c|c|c|c|c|c|c|c|c|c|c|}
\hline & \multirow{2}{*}{ model } & \multicolumn{2}{|c|}{ Unnormalized coefficient } & \multirow{2}{*}{$\begin{array}{c}\begin{array}{c}\text { Standardization } \\
\text { coefficient }\end{array} \\
\text { Beta }\end{array}$} & \multirow{2}{*}{$\mathrm{t}$} & \multirow{2}{*}{ Significant } & \multicolumn{3}{|c|}{ Correlation } & \multicolumn{2}{|c|}{ Collinear statistics } \\
\hline & & B & Standard error & & & & Zero order & Partial & section & Tolerance & VIF \\
\hline \multirow{5}{*}{1} & (constant) & 0.040 & 0.200 & & 0.198 & 0.843 & & & & & \\
\hline & experience staff & 0.140 & 0.062 & 0.152 & 2.260 & 0.025 & 0.699 & 0.184 & 0.096 & 0.400 & 2.497 \\
\hline & experience promotion & 0.451 & 0.077 & 0.448 & 5.883 & 0.000 & 0.820 & 0.438 & 0.251 & 0.313 & 3.197 \\
\hline & experience mode & 0.179 & 0.067 & 0.164 & 2.689 & 0.008 & 0.677 & 0.217 & 0.115 & 0.485 & 2.060 \\
\hline & experience environment & 0.212 & 0.090 & 0.194 & 2.369 & 0.019 & 0.774 & 0.192 & 0.101 & 0.270 & 3.707 \\
\hline
\end{tabular}

a. Dependent variable: cognitive experience.

intention $(\mathrm{P}<0.001)$. The consumer's brand experience will promote or influence the consumer's purchase intention, which in turn affects the purchase behavior. A good experience is conducive to increasing the willingness to buy and driving sales.

\section{Conclusions}

Product experience and environmental experience are the more concerned part of the brand's target consumer group, and other experiential promotion links, including brand promotion and celebrity endorsement, may be due to differences in expressions or communication and acceptance, and the impact of the moderately high age of this survey shows the weaker interest and attention of consumers.

In the factor analysis, we can know that in the dimension of experience mode, the factors most relevant to the consumer brand experience are the product component experiment, the free product use selection, and the brand cultivation classroom. People are more inclined to pay attention to the product utility itself, and eager to get autonomous experience space, which also puts more appropriate requirements for the communication of the promotion personnel. Another factor brand training class reflects the target consumer group's pursuit of a better life, a higher level of pursuit and yearning, while bringing a good experience, which can enhance the brand's image.

In the experience environment dimension, six factors including high-end promotion location, appropriate promotion frequency, exquisite environment layout, soothing environmental music, wonderful performing arts performance and delicious tea break snack are all closely related to brand experience. It shows that consumers pay more attention to the experience environment, and a more comfortable experience environment may bring higher satisfaction to consumers and promote the formation of purchase intentions. Creating a better experience space has become a very important research topic for brands.

In the dimension of experiential personnel, since the order of factors in the order of importance is mostly in the middle and rear positions, it can be roughly understood that this dimension has weak influence on the brand experience of 
consumers, including the promotion staff and the attitude of enthusiasm, free of charge. The three factors of the hand care service and the relationship with the promotion staff can be seen in the interpersonal promotion, relationship marketing still has a greater impact in the domestic market, and the traditional free promotion is still more attractive to consumers.

At the level of experience promotion, the three factors with higher relevance are distinct brand concept, figurative star, and unique brand image. The influence of the brand's origin story is not as significant as the brand expects, and most consumers are more rational. However, the brand concept of SK-II brand "rewriting destiny" has obtained high evaluation and recognition. Brand image promotion and endorsement stars are more in line with the preferences of target consumer groups, but may need to be focused on the brand promotion.

Through reliability analysis and regression analysis, we can understand that although the data of this survey is small, it still has high credibility due to the accurate distribution of targeted populations. In the regression analysis of brand experience and purchase intention, we can see that the effect of brand experience promotion is indeed highly correlated with customer purchase intention.

\section{Conflicts of Interest}

The authors declare no conflicts of interest regarding the publication of this paper.

\section{References}

[1] Zhao, L. and Wen, J.H. (2010) The Effectiveness of Online Sales Promotion under Different Shopping Experience. 2010 International Conference on Computer Application and System Modeling, Taiyuan, 22-24 October 2010, 334-337.

[2] Zhang, L.-X. and Tang, S.-L. (2010) An Empirical Study on Impact of Sales Promotion on Brand Loyalty of Service Enterprise. 2010 International Conference on Management and Service Science, Wuhan, 24-26 August 2010.

[3] Cui, J.H., Pan, Y.Z. and Wang, L.Y. (2012) Impact of Online Review on Sales: An Empirical Investigation of Experience Products with Different Popularities. 2012 International Conference on Management of E-Commerce and E-Government, Beijing, 20-21 October 2012.

[4] Fan, Y.-N. and Chern, C.-C. (2013) An Agent Model for Incremental Rough Set-Based Rule Induction: A Big Data Analysis in Sales Promotion. 2013 46th Hawaii International Conference on System Sciences, Wailea, Maui, HI, 7-10 January 2013, 985-994.

[5] Wang, L. and Liu, J.-P. (2013) Study on Different Strategies of Sales Promotion Considering Negative Spillover Effect in Dual-Channel. 2013 10th International Conference on Service Systems and Service Management, Hong Kong, 17-19 July 2013, 326-331.

[6] Fang, Y.-M., Chen, K.-M. and Hsu, C.-W. (2014) The Study on the Correlation between Emotional Design and Emotion-Taking the Conditioning Process of Lemonade for Example. 2014 4th International Conference on Digital Information and Communication Technology and Its Applications, Bangkok, 6-8 May 2014, 435-439. 
[7] Diao, X.Y. and He, L.H. (2014) An Empirical Research on the Influence of Perceived Value On Buyers' Purchase Intention-Based on the Regulation of Freight. 201433 rd Chinese Control Conference, Nanjing, 28-30 July 2014, 3445-3449.

[8] Sylvain, A., Doniec, A., Mandiau, R. and Lecoeuche, S. (2014) Purchase Intention Based Model for a Behavioural Simulation of Sale Space. 2014 IEEE/ WICI ACM International Joint Conferences on Web Intelligence (WI) and Intelligent Agent Technologies (IAT), Warsaw, 11-14 August 2014, 318-324. https://doi.org/10.1109/WI-IAT.2014.183

[9] Luo, W. and Wang, Z. (2004) Skincare Industry Analysis Report. Daily Chemical Science, No. 5, 6-8.

[10] Editorial Department of this journal (2014) Overview of the Development of Skin Care Industry in China. Journal of Daily Chemical Science, No. 7, 11-13.

[11] (2014) Overview of the Development of China's Skin Care Industry (I). Domestic and Foreign Fragrance Information, No. 9, 2-3.

[12] (2014) Overview of the Development of China's Skin Care Industry (Below). Domestic and Foreign Fragrance Information, No. 10, 1-2.

[13] Guo, H. (2011) Research on Luxury Marketing Strategy Based on Consumer Experience. Shanghai Jiao Tong University, Shanghai.

[14] Liu, Y. (2012) Research on Luxury Marketing Strategy in Department Stores. Shandong University, Shandong.

[15] Sun, J. (2007) Research on Brand Strategy under Experience Marketing. Times Economics and Trade, No. 8, 162-163.

[16] Wang, L. and Qian, X.C. (2007) Definition of Experience Connotation and Experience Marketing Strategy Research. Journal of Huazhong University of Science and Technology, No. 11, 43-47.

[17] Qi, S.H. and Peng, H.M. (1991) Analysis of the Effect Evaluation Method of Market Promotion and Publicity. Nankai Economic Research, No. 3, 51-55.

[18] Zhao, F. (2002) On the Role of Promotional Propaganda in Marketing. Economist, No. 7, 183-184.

[19] Hao, L.G. (2008) Consumer Response to Promotion and Promotion Effect. Southwest Jiaotong University, Tangshan.

[20] Hao, L.G. (2008) How Corporate Promotion Activities Affect Consumer Behavior: A Theoretical Review. East China Economic Management, No. 4, 132-136.

[21] Yin, W.L. (2007) Experience Marketing-New Weapons for Terminal Promotion. Special Economic Zone, No. 7, 303-304.

[22] Gu, W. (2012) Research on Promotion Strategy in the Background of Experience Marketing. China Business, No. 25, 93-94.

[23] Li, Z.D. (2014) Experiential Promotion Promotes the Development of Qinghai Tourism Industry. Modern Business, No. 20, 72-73.

[24] Fan, H., Yang, Z. and Xu, N. (2006) Experiential Consumption into a New Promotion for Merchants. Jiangsu Economic News, 07-13A02.

[25] Wang, H.X. (2007) Empirical Research on Consumer Skin Care Brand Recognition. Xi'an University of Technology, Xi'an.

[26] Zhang, J. (2014) Research on the Influence of Brand Memory on Consumers' Purchase Intention. China University of Mining and Technology, Xuzhou.

[27] Liang, Y.X. (2016) The Inevitability of Experiential Marketing for Women's Skin Care Products. China Market, No. 5, 31-35. 
[28] Lü, J.L. (2001) Investigation and Analysis of Skincare Consumer Market. Journal of Minxi Vocational University, No. 2, 38-40.

[29] Zhang, X.D. (2003) Analysis of the Development Trend of China's Skin Care Products Market. Cleaning the World, No. 7, 82-83.

[30] Yin, J.Z. and Li, P. (2005) Research on the Countermeasures to Improve the Competitiveness of China's Skin Care Products Enterprises. Technology and Economy, No. 10, 62-64.

[31] Kingdom of the Kingdom. (2005) Procter \& Gamble and Unilever Marketing Analysis. Tsinghua University, Beijing.

[32] Song, M.Y. and Xiao, H.J. (2012) The Impact of Experience Marketing on Consumers' Willingness to Purchase-Taking $3 \mathrm{G}$ Business as an Example. Technical Economy, 31, 123-127.

[33] Gu, W. (2012) Research on Promotion Strategy in the Background of Experience Marketing. China Business, No. 55225, 93-94.

[34] Xu, F. (2011) Research on the Marketing Network of Cosmetics Company in S Company. Nanjing Agricultural University, Nanjing.

[35] Cheng, R. (2007) Research on Enterprise Experience Marketing Strategy Based on Consumer Behavior. Wuhan University of Technology, Wuhan.

[36] Six Major Diseases of Promotion Modernization of Shopping Malls (2004), No. 07, 67-68.

[37] Liu, J., Zhou, M.H. and Ye, N. (2009) A Review of Research on Consumer Propensity. Jiangsu Business Theory, No. 30111, 19-20.

[38] Wang, Q.-N. (2011) Research on Brand Positioning of Skin Care Products of W Company. Guangdong University of Technology, Guangdong. 